GU J Sci, Part C, 6(3): 705-714 (2018)

Gazi Üniversitesi
Fen Bilimleri Dergisi
PART C: TASARIM VE TEKNOLOJI
dergipark.gov.tr/http-gujsc-gazi-edu-tr

\title{
Karbon Fiber Takviyeli Kompozit Malzemelerinin Frezelenmesinde Meydana Gelen Yüzey Pürüzlüğünün Değerlendirilmesi ve Matematiksel Modellenmesi
}

\author{
Selçuk YAĞMUR ${ }^{1}$, Abdullah KURT ${ }^{1}$, Ulvi ŞEKER ${ }^{1}$ \\ ${ }^{I}$ Gazi Üniversitesi, Teknoloji Fakültesi, İmalat Mühendisliği Bölümü, 06500, Yenimahalle/ANKARA
}

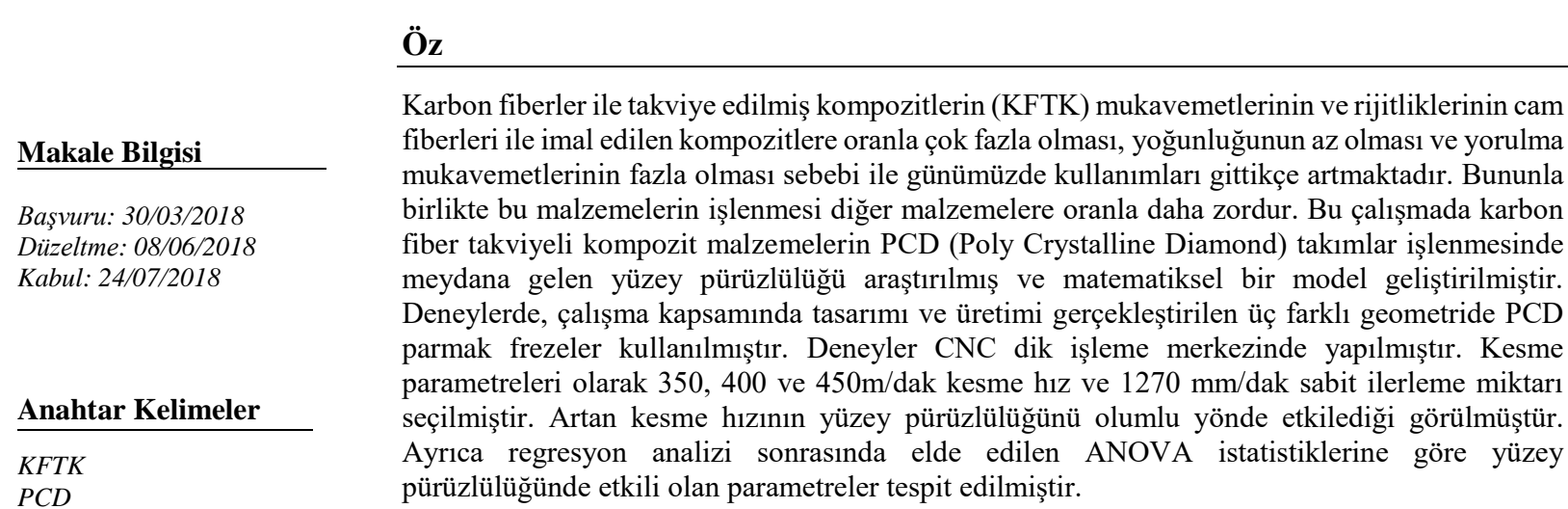

Yüzey Pürüzlülüğ̈̈

\section{Keywords}

CFRP

$P C D$

Surface Roughness

\section{The Evaluation and Mathematical Modelling of Surface Roughness in Milling of Carbon Fiber Reinforced Composite Materials}

\begin{abstract}
The usage of carbon fiber reinforced composite materials increase at the present time; owing to their low density, fatigue resistance, higher strength and higher rigidity than the composites produced with glass fibers. In addition to this, these materials are hard to cut materials comparing to the others. In this study, surface roughness formation was investigated by using PCD cutting tools in milling of carbon fiber reinforced composite materials. Additionally, a mathematical model was built. During the experiments, PCD end mills with three different geometries were used. These end mills designed and produced as a part of the study. Experiments were conducted on a CNC vertical machining center. Three different cutting speeds (350, 400 and $450 \mathrm{~m} / \mathrm{min}$ ) and a constant feed rate $(1270 \mathrm{~mm} / \mathrm{min})$ were used as cutting parameters. Increasing cutting speed effects surface roughness values positively. Moreover, the efficient parameters on surface roughness values were determined according to acquired ANOVA statistics following regression analysis.
\end{abstract}

\section{GÍRIŞ (INTRODUCTION)}

Teknolojinin gelişimi, son yüzyılda bilgisayarların da devreye girmesiyle beraber büyük bir ivme kazanmıştır. Doğadan elde edilen malzemelerin sınırlı olmasından dolayı, malzeme özellikleri bu büyük gelişimeye ayak uyduramamış ve sanayi için temel bir girdi olan malzeme ve malzeme biliminde gelişme kaçınılmaz bir duruma gelmiştir [1]. Malzeme biliminde meydana gelen gelişmelere paralel kompozit malzemelerin üretilmesi ve endüstriyel alanda kullanımı hız kazanmıştır.

Kompozit malzemelerin, çeliğin yerini almasıyla \%60-80 oranında ve alüminyumun yerini almasıla ise \%20-50 oranında ağırlıktan kazanım mümkün hale gelmiştir. Günümüzde kompozitler birçok mühendislik uygulamaları için tercih edilen malzemeler gibi gözükmektedir. Bu; ağırlık kazançları, enerjinin giderek artan bir sorun haline geldiği çă̆ımızda enerjide önemli tasarruflar sağlamaktadır [2]. 
Kompozit malzemelerin avantajlarının yanı sıra imalat güçlükleri gibi dezavantajlar da mevcuttur. Farklı sektörlerde güncel teknolojinin vazgeçilmez malzemelerinden bir olarak gözüken fiber takviyeli kompozit malzemelerin işlenmesi diğer malzemelere oranla daha zordur. Bu durum kesici takımlar açısından çok seçici olmayı gerektirir. Bu malzemelere en yaygın uygulanan talaş kaldırma işlemleri delme, parmak freze ile işleme gibi işlemlerdir. Kompozitler keskin bir kesici uç ile işlenmelidir. Kesici kenarın aşırı aşınması halinde fiberler kesilmeyip kopacak, bu da tabakaların ayrılmasına neden olacaktır. Kompozitlerin işlenmesi için çok ince taneli sinterlenmiş karbür ve çok kristalli elmas (PCD) takımlar kullanılır.

$\mathrm{Bu}$ işleme zorluklarının aşılmasına yardımcı olmak için son dönemlerde birçok çalışmacı kompozit malzemelerin işlenebiliriliği ile ilgili çalışmalar yapmıştır.

Çalışmalarda frezeleme işlemlerinde faklı kesme parametrelerinin yüzey pürüzlülüğü, kesme kuvvetleri ve delaminasyon yayılmasına etkileri araştırılmıştır ve bununla birlikte çeşitli modelleme yöntemleri kullanmışlardır[3-6]. Çalıșmalar sadece frezeleme işlemleri ile sınırlı kalmamıș ve delme ișlemleri içinde yapılmıştır. Gaitonde ve arkadaşları karbon fiber takviyeli kompozit malzemelerin yüksek hızlarda delinmesinde meydana gelen delaminasyon yayılmasını araştırmışlardır [7]. Ayrıca literatürde karbon fiber takviyeli kompozitlerin delinebilirliği ile ilgili pek çok araştırmaya rastlamak mümkündür [8-14].

\section{MATERYAL ve METOT (MATERIAL and METHOD)}

Deneylerde kullanılacak olan karbon fiber takviyeli kompozit malzemeler havacılık ektöründe yaygın olarak kullanılmaktadır. Bu malzemeler Odak Kompozit Teknolojileri A.Ş. tarafından havacılık sektöründe kullanılan malzeme özelliklerine uygun olarak üretilmiştir. Deneylerde kullanılan malzemelere ait ön ve yan yüzeylerinden alınmış mikroyapı fotoğrafları Resim 1'de verilmiştir.

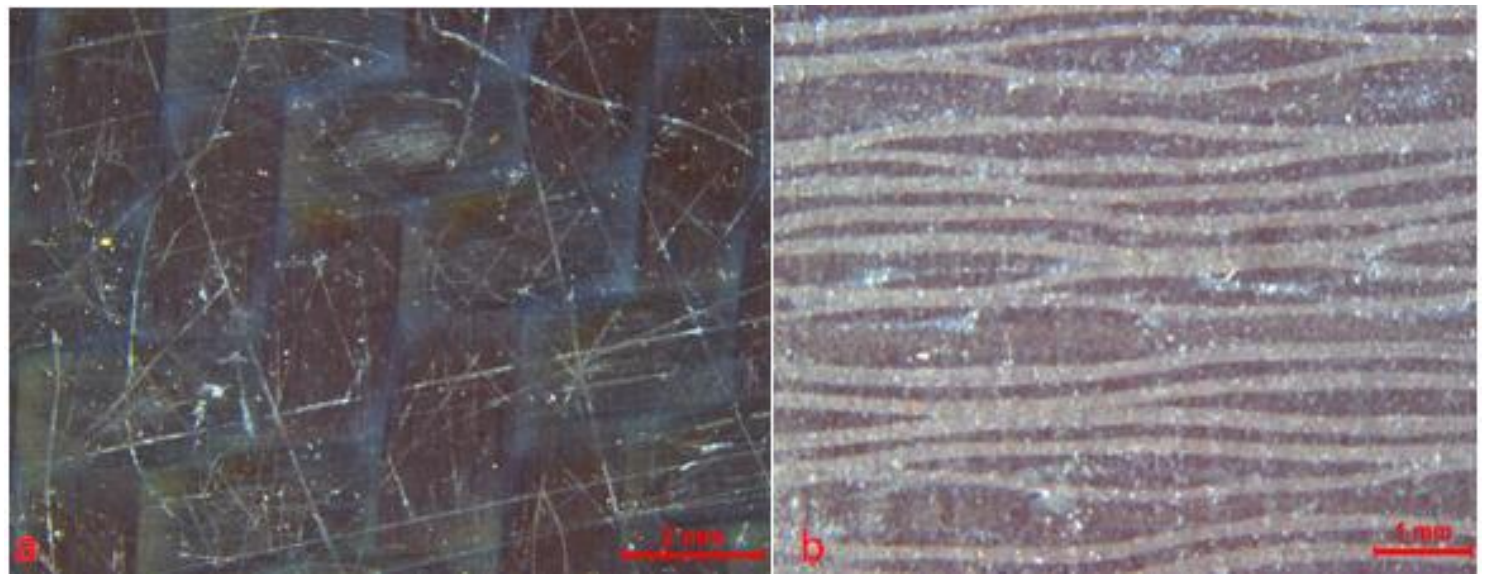

Resim 1. Deneylerde kullanılan malzemelere ait mikroyap fotoğrafları

a) Ön yüzey görüntüsü b) Yan yüzey görüntüsü

Deneylerde çalışma kapsamında tasarımı ve üretimi gerçekleştirilen üç farklı takım kullanılmıştır. Bu takımlar Takım 1, Takım 2 ve Takım 3 olarak adlandırılmış olup T1, T2 ve T3 şeklinde kodlanmıştır. Geliştirilen takımların üç kesici ağzından biri sağ biri sol helis açısına sahipken üçüncü kenar, takımın dalmasını sağlamak amacıyla, düz olarak imal edilmiştir. Helis açıları aynı olan bu kesici takımlara iki ön boşluk açıları 1 numaralı takım için birinci boşluk açısı $8^{\circ}$, ikinci boşluk açısı $17^{\circ} .2$ numaralı takım için birinci boşluk açısı $11^{\circ}$, ikinci boşluk açısı $20^{\circ}$ ve 3 numaralı takım için birinci boşluk açı1S1 $13^{\circ}$, ikinci boşluk açısı $25^{\circ}$ şeklindedir. Takımlara ait bu boşluk açıları Şekil1'de verilmiştir.

Deneylerde kullanılan kesme hızları ve ilerleme miktarı kesici takım firmaları tarafından tavsiye edilen KFTK malzemelerin işlenmesinde kullanılan değerler arasından belirlenmiştir. 

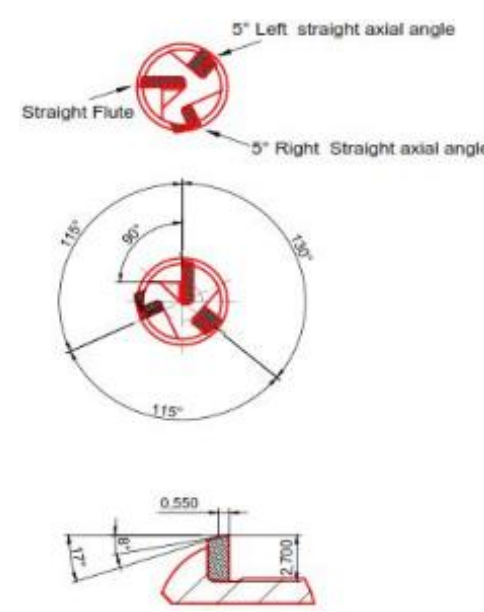

a)

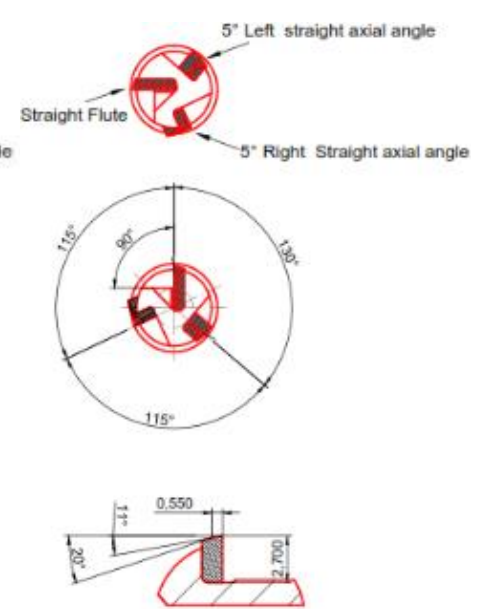

b)
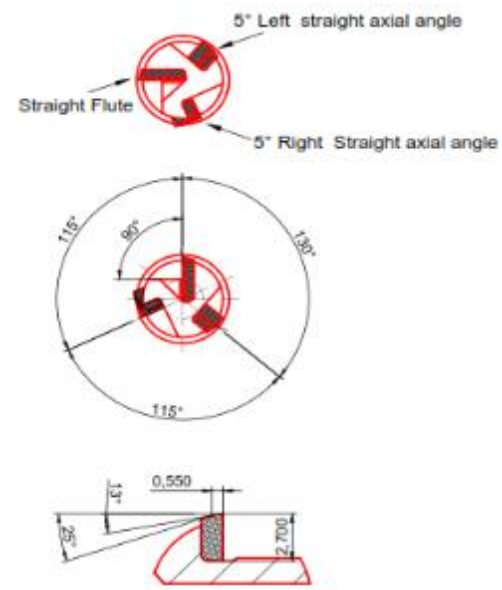

c)

Şekil 1. Takımlara ait bu boşluk açıları
a) $T 1$
b) $T 2$
c) $T 3$

İşlenebilirlik deneyleri Gazi Üniversitesi Teknoloji Fakültesi İmalat Mühendisliği Bölümünde Johnford VMC-550 marka CNC dik işleme merkezinde gerçekleştirilmiştir. Bu tezgâhın özellikleri Tablo 1'de verilmiştir.

Tablo.1. Deneylerde kullanılan tezgâhın teknik özellikleri

\begin{tabular}{|l|l|}
\hline Tezgahın Gücü & $5 \mathrm{KW}$ \\
\hline En Yüksek Devir Sayısı & $6000 \mathrm{dev} / \mathrm{dak}$ \\
\hline Sırayla x, y, z ekseni & $600,500,600 \mathrm{~mm}$ \\
\hline Ölçü Hassasiyeti & $0,001 \mathrm{~mm}$ \\
\hline Kontrol Ünitesi & Fanuc \\
\hline
\end{tabular}

Yüzey kalitesini belirlemek amacıyla, işlenmiş yüzeylerde ortalama yüzey pürüzlülük (Ra) değerlerini ölçmek için teknik özellikleri Tablo 2'de verilen Mahr Perthometer M1 cihazı kullanılmıştır. Ölçüm yapılmadan önce cihazın kalibrasyonu yapılmıştır. İşleme sonrası elde edilen yüzeyden işleme yönüne paralel olmak üzere üç yüzeyde onar adet ölçüm (bir yüzeyde on adet ölçüm yapılmasının sebebi kompozit içinde matris ve elyafın homojen olmaması ve örgü elyaf kullanılmasıdır) gerçekleştirilmiş olup bu değerlerin aritmetik ortalaması ortalama yüzey pürüzlülük değeri olarak kabul edilmiştir. Yüzey pürüzlülük ölçüm düzeneği Resim 1.'de' gösterilmiştir. 
Tablo 2. Mahr Perthometer M1 yüzey pürüzlülüğü ölçüm cihazının teknik özellikleri

\begin{tabular}{|l|l|}
\hline Model ve Özellikler & Mahr Perthometer-M1 \\
\hline İğne uç yarıçapı & $2 \mu \mathrm{m}$ \\
\hline Ölçme aralığı & $100-150 \mu \mathrm{m}$ \\
\hline Tarama hızı & $0,5 \mathrm{~m} / \mathrm{s}$ \\
\hline Tarama kuvveti & $0,75 \mathrm{mN}$ \\
\hline Profil çözünürlüğü & $12 \mathrm{~mm}$ \\
\hline Filtre & Gausian \\
\hline Ölçülebilen parametreler & Ra, Rz, Rmax \\
\hline Örnekleme uzunluğu & $0,25-0,8-2,5 \mathrm{~mm}$ \\
\hline Ölçme uzunluğu (L) & $1,75-5,6-17,5 \mathrm{~mm}$ \\
\hline
\end{tabular}

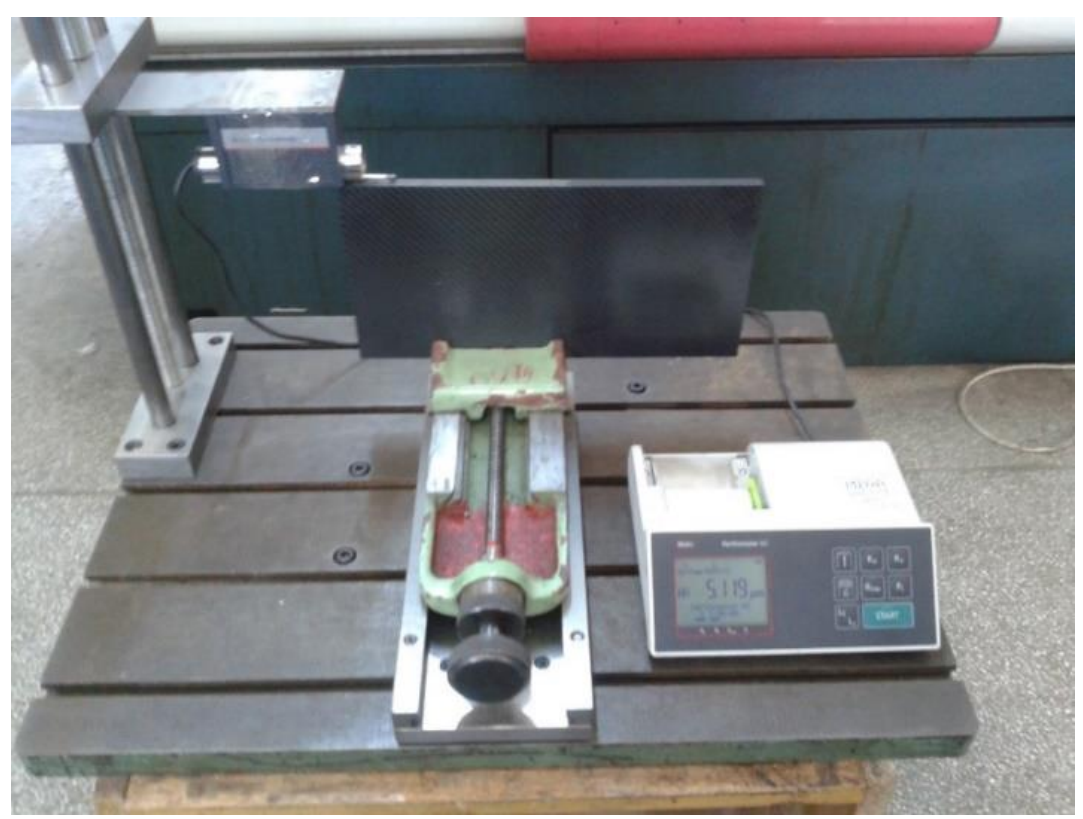

Resim 2. Yüzey pürüzlülük ölçüm düzeneği

KFTK malzemenin CNC dik işleme merkezinde işlendiği bu çalışmada kurulan deney düzeneğinin şematik gösterimi Şekil 1'de verilmiştir. 


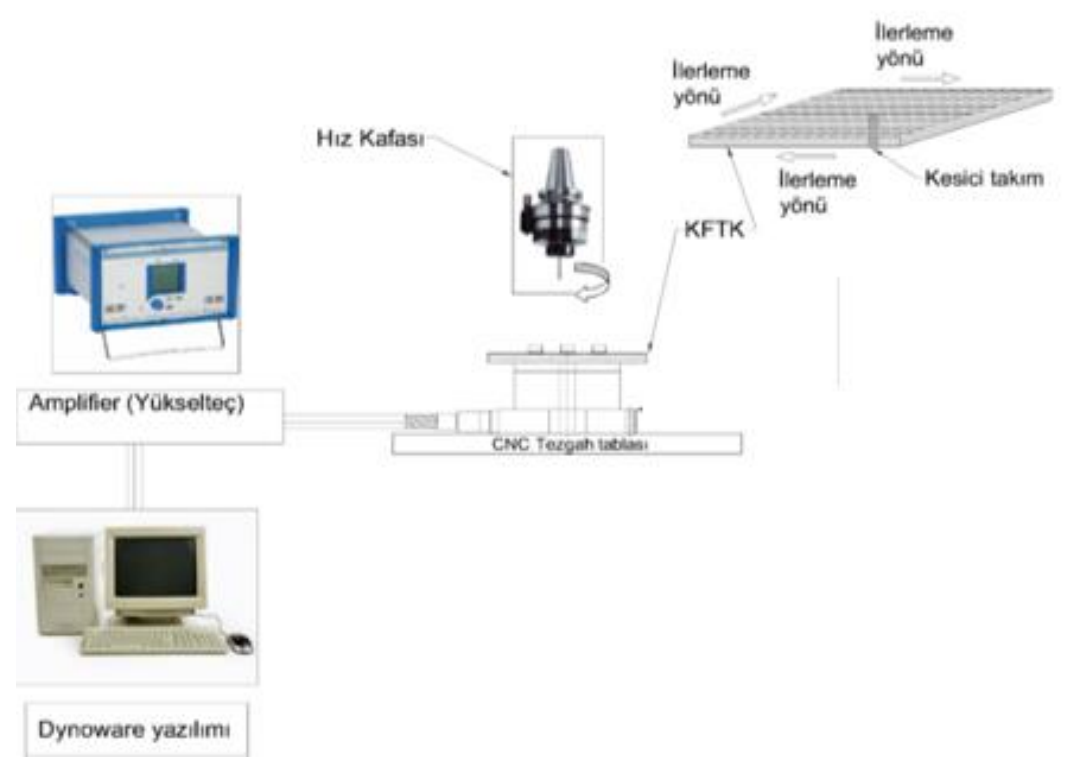

Şekil 2. Deney düzeneğinin şematik olarak gösterimi

Regresyon analizinde, gerçekleştirilen toplam 9 deneyde kullanılan X1, X2, X3 bağımsız değişkenleri Tablo 3'te gösterilmiştir.

Tablo 3. Deney/Analiz parametreleri

\begin{tabular}{|c|c|c|c|}
\hline $\begin{array}{c}\text { Deney } \\
\text { no }\end{array}$ & $\begin{array}{c}\text { girdi1 } \\
(\mathrm{X} 1)\end{array}$ & $\begin{array}{c}\text { girdi2 } \\
(\mathrm{X} 2)\end{array}$ & $\begin{array}{c}\text { girdi3 } \\
(\mathrm{X} 3)\end{array}$ \\
\hline 1 & 350 & 8 & 17 \\
\hline 2 & 400 & 8 & 17 \\
\hline 3 & 450 & 8 & 17 \\
\hline 4 & 350 & 11 & 20 \\
\hline 5 & 400 & 11 & 20 \\
\hline 6 & 450 & 11 & 20 \\
\hline 7 & 350 & 13 & 25 \\
\hline 8 & 400 & 13 & 25 \\
\hline 9 & 450 & 13 & 25 \\
\hline
\end{tabular}

Tablo 3'te verilen X1 kesme hızını, X2 birinci boşluk açısnı ve X3 ikinci boşluk açısını ifade etmektedir. Literatür [15] ve çok değişkenli doğrusal regresyon analizi esasları referans alınarak S1 için Eş.1'de gösterilen lineer model geliştirilmiştir:

$$
\hat{S}_{1}=w+w_{1} \cdot X_{1}+w_{2} \cdot X_{2}+w_{3} \cdot X_{3}
$$

Burada w model sabitini; w1, w2, ve w3 ise sırasıyla X1, X2 ve X3 bağımsız değişkenleri (girdiler) için sabitleri göstermektedir. Ŝ1 ise deney/gözlem sonuçları olan gerçek sonuçlar (veya bağımlı değişken/çıktı, S1) doğrultusunda hesaplanan model sonuçlarını ifade etmektedir. 


\section{SONUÇLARIN DEĞERLENDİRILMESİ (3. EVALUATION of RESULTS)}

\subsection{Deney Sonuçlarının Değerlendirilmesi (3.1. Evaluation of Test Results)}

Tasarımı ve üretimi yapılan üç farklı PCD parmak freze kullanılarak yapılan deneyler sonrasında elde edilen veriler Tablo 4'te toplu halde verilmiştir. Tablo 4'teki veriler kullanılarak hazırlanan grafikte kesme hızı ve yüzey pürüzlüğü arasındaki ilişki Şekil 2'de, verilmiştir.

Tablo 4. Deney girdilerine bağlı olarak elde edilen çıktılar

\begin{tabular}{|c|c|c|c|c|}
\hline $\begin{array}{l}\text { Deney } \\
\text { No }\end{array}$ & $\begin{array}{c}\text { Kesme Hizl } \\
(\mathrm{m} / \mathrm{dak})\end{array}$ & $\begin{array}{l}\text { İlerleme } \\
\text { (mm/dak) }\end{array}$ & $\begin{array}{l}\text { Kesici } \\
\text { Tak1m }\end{array}$ & $\begin{array}{c}\text { Ortalama Yüzey } \\
\text { Pürüzlülüğü Ra }(\mu \mathrm{m})\end{array}$ \\
\hline 1 & 350 & \multirow{9}{*}{1270} & \multirow{3}{*}{$\mathrm{T} 1$} & 1,383 \\
\hline 2 & 400 & & & 0,942 \\
\hline 3 & 450 & & & 0,545 \\
\hline 4 & 350 & & \multirow{3}{*}{$\mathrm{T} 2$} & 2,274 \\
\hline 5 & 400 & & & 2,036 \\
\hline 6 & 450 & & & 1,55 \\
\hline 7 & 350 & & \multirow{3}{*}{$\mathrm{T} 3$} & 1,738 \\
\hline 8 & 400 & & & 1,336 \\
\hline 9 & 450 & & & 1,144 \\
\hline
\end{tabular}

Deneyler sonrasında elde edilen ortalama yüzey pürüzlülük değerlerinin kesme hızı ve takım geometrisine bağlı olarak değişimleri Şekil 2'deki grafiklerde gösterilmiştir. Şekil 2'deki grafikler incelendiğinde kesme hızının artışı genel olarak ortalama yüzey pürüzlülüğü değerlerini azalmasına sebep olduğu görülmektedir. Artan kesme hızlarının ortalama yüzey pürüzlülügünü iyileştirmesi beklenen bir durumdur ve literatürdeki çalışmalarda da bu durum gözlemlenmiştir [16].

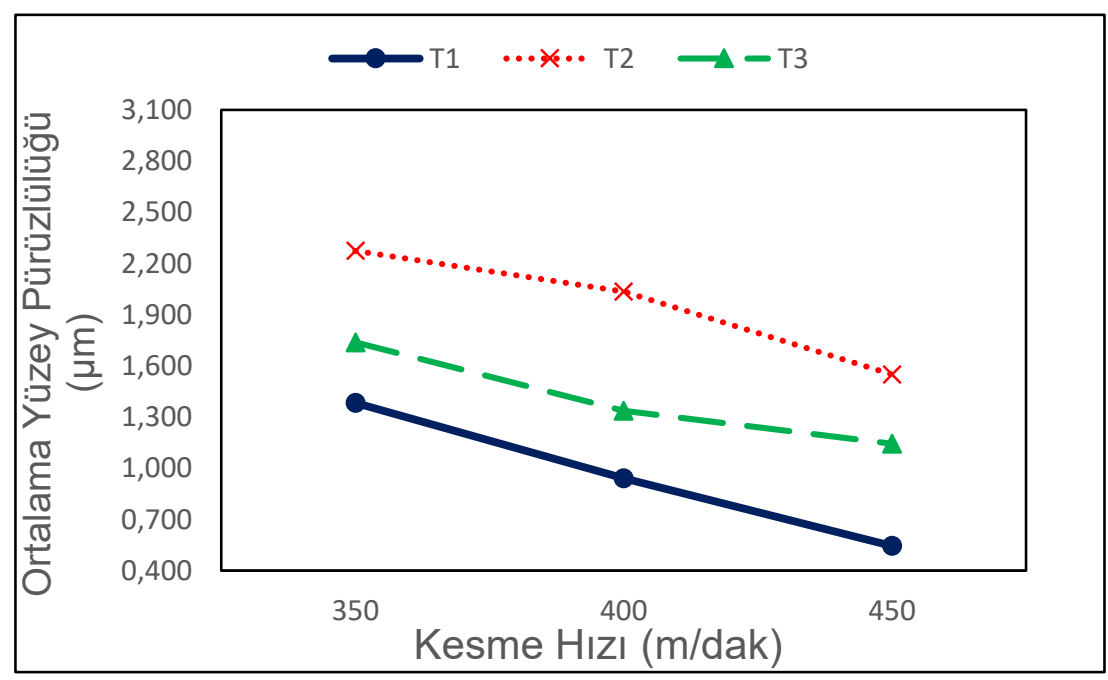

Şekil 3. Kesme hızı ve takım geometrisine bağhl olarak ortalama yüzey pürüzlüğündeki değişim 
Şekil 2'deki grafikten de görülebileceği gibi en düşük ortalama yüzey pürüzlülüğü değerleri 1 numaralı (T1) takımla meydana gelirken en yüksek ortalama yüzey pürüzlülügü değerleri 2 numaralı (T2) takımda meydana gelmiştir. T1 kodlu takımın 1. ön boşluk ve 2. ön boşluk açısı diğer iki takıma nazaran daha düşüktür. Ön boşluk açılarının düşük olması ortalama yüzey pürüzlülüğü değerleri anlamında olumlu etki yapmıştır. Fakat T2 ve T3 ele alındığında T2 kodlu takım T3'e oranla daha düşük boşluk açılarına sahip olmasına rağmen ortalama yüzey pürüzlülük değerleri daha yüksek çıkmıştır. Geliştirilen takımlar yüzey pürüzlülüğü açısından değerlendirdiğinde; T1 en iyi geometriye sahipken onu T3 ve T2 izlemektedir.

En iyi performansı gösteren T1 kodlu takım en düşük boşluk açılarına dolayısıyla en yüksek kama açısına sahiptir. T1 kodlu takımın en iyi performansı göstermesi, büyük kama açısına sahip olmasına atfedilebilir. Kama açısının büyük olması takımın aşınma direncini arttırmakta ve takım daha az aşınmaktadır. Bu sebeple yüzey kalitesi daha iyi meydana gelmektedir.

T2 ve T3 açısından bu durum incelenecek olursa; T2 daha büyük kama açısına sahiptir bu durum T3'e göre aşınma direncinin daha fazla olduğu anlamına gelmektedir. Fakat T3 kodlu takımın kama açısının T2'ye göre düşük olması daha keskin olmasını sağlamıştır. Bu durum T3'te takımın fiberlerin kesmesi kolaylaşmış ve bu sayede T2'ye oranla daha iyi yüzey kalitesi elde edilmesini sağlamıştır.

\subsection{Deney Sonuçlarının Modellenmesi (3.2. Modeling of Experimental Results)}

Deneyler sonucunda elde edilen ortalama yüzey pürüzlülüğü $(\mathrm{Ra})$, değerleri için regresyon denklemi çıkartılmıştır. Regresyon modelinde denklemlerin oluşturulması için Excel programı kullanılmıştır. Model denklemi için Minitab 15 Programı kullanılarak sağlama yapılmıştır. Minatab15 programı ile elde edilen model sonuçları ile Excel programında elde edilen model sonuçları birbirini doğrulamıştır.

Tablo 5. Deney sonuçları ve Model sonuçları

\begin{tabular}{|c|c|c|c|c|c|}
\hline & \multirow{2}{*}{ Deney Sonucu } & \multirow{2}{*}{ Model Sonucu } \\
\hline & & & & & \\
\hline $\begin{array}{l}\text { Deney } \\
\text { No }\end{array}$ & $\begin{array}{c}\text { Kesme Hizı } \\
(\mathrm{m} / \mathrm{min})\end{array}$ & $\begin{array}{l}\text { İlerleme } \\
(\mathrm{mm} / \mathrm{min})\end{array}$ & $\begin{array}{l}\text { Kesici } \\
\text { Takım }\end{array}$ & $\begin{array}{l}\text { Ortalama Yüzey } \\
\text { Pürüzlülüğü Ra } \\
\qquad(\mu \mathrm{m})\end{array}$ & $\begin{array}{c}\text { Ortalama Yüzey } \\
\text { Pürüzlülüğü Ra }(\mu \mathrm{m})\end{array}$ \\
\hline 1 & 350 & \multirow{9}{*}{1270} & \multirow{3}{*}{$\mathrm{T} 1$} & 1,383 & 1,197 \\
\hline 2 & 400 & & & 0,942 & 0,881 \\
\hline 3 & 450 & & & 0,545 & 0,673 \\
\hline 4 & 350 & & \multirow{3}{*}{$\mathrm{T} 2$} & 2,274 & 2,587 \\
\hline 5 & 400 & & & 2,036 & 1,906 \\
\hline 6 & 450 & & & 1,55 & 1,455 \\
\hline 7 & 350 & & \multirow{3}{*}{$\mathrm{T} 3$} & 1,738 & 1,858 \\
\hline 8 & 400 & & & 1,336 & 1,368 \\
\hline 9 & 450 & & & 1,144 & 1,045 \\
\hline
\end{tabular}

Model' e göre her bir deney için yüzey pürüzlülüğü, açısından hangi parametrelerin daha etkili olduğu varyans analizi ile yapılmıştır. Kesme hızı, birinci boşluk açısı $(\beta)$ ve ikinci boşluk açısı $(\theta)$ faktörleri dikkate alınarak Model için eşitlik 2'deki denklem elde edilmiştir.

$$
\mathrm{Si}=\mathrm{c} 0 . \mathrm{Vc} 1 . \beta \mathrm{c} 2 . \theta \mathrm{c} 3
$$




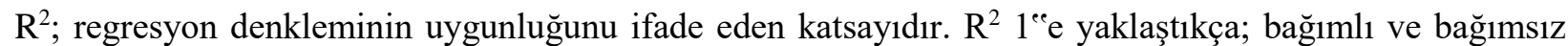
değişkenler arasındaki ilişkiyi ifade eden regresyon modelinin, istatistiksel olarak gerçekliğe yakınlığının arttığı kabul edilmektedir. $\mathrm{R}^{2} 1$ 'e yaklaştıkça bağımsız değişkenler bağımlı değişkeni tam açıklar. $\mathrm{R}^{2}$ nin $\% 80$ ve üzeri kabul edilebilir sınırlar içindedir ve kuvvetli ilişkiye sahiptir [17-19]. Her bir model çıktısı ile gerçek değerlerin daha rahat kıyaslanabilmesi için deney sonuçları ve Model'e göre grafikler oluşturulmuştur detaylı olarak değerlendirilmiştir.

Model' e göre ortalama yüzey pürüzlülük değerleri için elde edilen regresyon istatistikleri ve varyans analizi sonuçları Tablo 6'da verilmiştir. Tablo 6' da da görüleceği üzere deney sonuçları ile model sonuçları arasındaki uyumu gösteren R2 değerinin 0,92 olarak hesaplanmıştır. $\mathrm{R}^{2} 1$ 'e yaklaştıkça geliştirilen modelin başarı oranı yükselir. Bu da ortalama yüzey pürüzlülüğü açısından modelin başarı oranının yüksek olduğu sonucunu doğurur.

Tablo 6. Ortalama yüzey pürüzlülüğ̈̈ (Ra) için Model 1 regresyon istatistikleri ve ANOVA bilgileri

\begin{tabular}{|c|c|c|c|c|c|c|}
\hline \multicolumn{5}{|c|}{ Regresyon İstatistikleri } & & \\
\hline $\mathrm{R} 2$ & Rçoklu & $\operatorname{Radj} 2$ & $\begin{array}{c}\text { Standart } \\
\text { Hata }\end{array}$ & Gözlem & & \\
\hline 0,92 & 0,96 & 0,88 & 0,063 & 9 & & \\
\hline \multicolumn{6}{|c|}{ ANOVA } & \\
\hline & df & SS & MS & $\mathrm{F}$ & $\begin{array}{c}\text { Anlamlilık } \\
\text { F }\end{array}$ & \\
\hline Regresyon & 3 & 0,263086 & 0,087695 & 21,4971 & 0,002755 & \\
\hline Hata (Fark) & 5 & 0,020397 & 0,004079 & & & \\
\hline \multirow[t]{3}{*}{ Toplam } & 8 & 0,283483 & 0,091775 & & & \\
\hline & & & & & & \\
\hline & Katsayilar & Std. Hata & T-değeri & P-değeri & Düşük \%95 & $\begin{array}{c}\text { Yüksek } \\
\% 95\end{array}$ \\
\hline Model sabiti & 7,821487 & 1,413662 & 5,5327864 & 0,002645 & 4,187555 & 11,455420 \\
\hline Kesme hizı & $-2,289180$ & 0,477493 & $-4,7941659$ & 0,004909 & $-3,516615$ & $-1,061746$ \\
\hline$\beta$ & 5,144470 & 0,917086 & 5,6095840 & 0,002489 & 2,787026 & 7,501914 \\
\hline$\theta$ & $-5,335953$ & 1,168274 & $-4,5673835$ & 0,006016 & $-8,339096$ & $-2,332811$ \\
\hline
\end{tabular}

Tablo 6'daki regresyon istatistikleri incelendiğinde ANOVA değerlerinde ortalama yüzey pürüzlülüğü açısından Anlamlılık F değerinin 0,002755 olduğu görülmektedir. Anlamlılık F değeri üç parametrenin birlikte değerlendirilmesi sonucu ortaya çıkan bir değerdir. Anlamlılık F değeri $<0,05$ olduğu için gruplar arasında anlamlı fark olduğu söylenebilir. Bu üç parametrenin ayrı ayrı P değerine bakıldığında, kesme hızı $\mathrm{P}$ değeri 0,004909, birinci boşluk açısı ( $\beta$ ) P değeri 0,002489 ve ikinci boşluk açısı $\mathrm{P}$ değerinin 0,006016 $(\theta)<0,05$ olduğu görülmektedir. Buradan Model için birinci boşluk açısı ve ikinci boşluk açısının yüzey pürüzlülüğü bakımından aynı anda etkili olduğu sonucu ortaya çıkar. Bu üç parametre arasında en etkili parametrenin P değeri sıfıra en yakın olan birinci boşluk açısının olduğunu söylemek mümkün olacaktır. Onu kesme hızı ve ikinci boşluk açısı izlemektedir. Model sonucunda elde edilen kesme kuvvetleri ile gerçek deney değerlerinin karşılaştırıldığı grafik Şekil 3'te verilmiştir. 


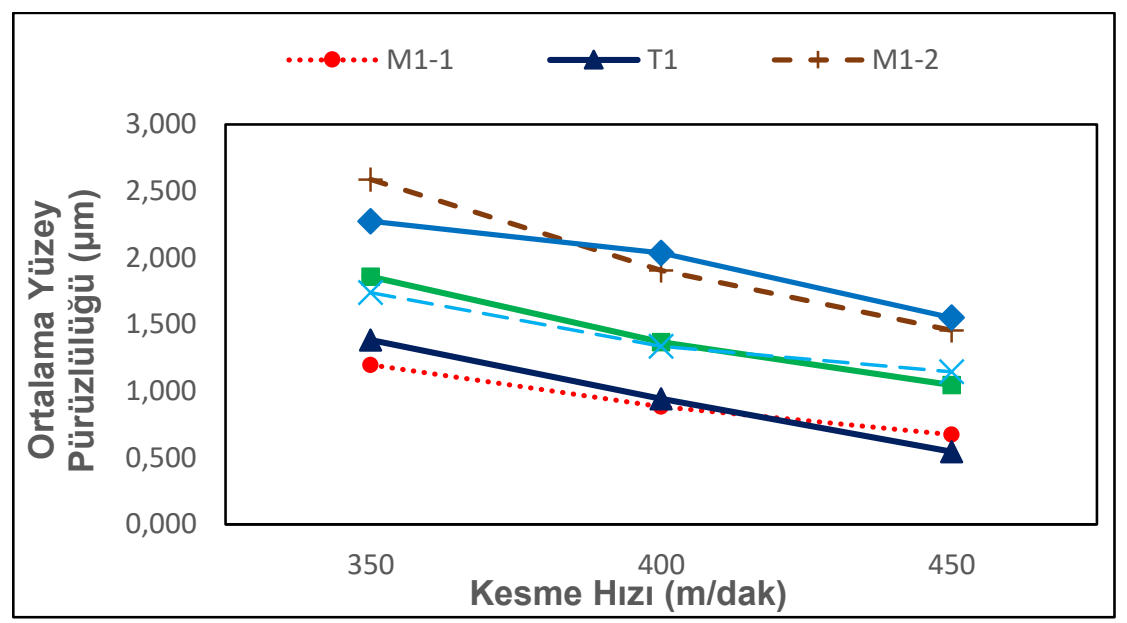

Şekil 4. Model sonuçlarının deney sonuçları ile ortalama yüzey pürüzlülüğü değerleri açsından karşılaş̧ırılması

\section{SONUÇ (CONCLUSION)}

Çalışma kapsamında tasarımı ve üretimi yapılan üç farklı geometriye sahip PCD takımla karbon fiber takviyeli kompozitlerin çevresel frezelenmesi meydana gelen yüzey pürüzlülüğü değerleri deneysel olarak incelenmiştir. Çalışma ve sonrasında elde edilen sonuçlar aşağıda verilmiştir.

- KFTK malzemelerin işlenmesinde kesme hızının artması, ortalama yüzey pürüzlülüğü, değerleri üzerinde olumlu etki yapmıştır.

- Tasarımı ve üretimi yapılan kesici takımlar arasında yüzey pürüzlülüğü değerleri açısından T1 kodlu takım en iyi performansı göstermiştir.

- T2 ve T3 kodlu takımlar birlikte değerlendirildiğinde; ortalama yüzey pürüzlülüğü, değerleri bakımından T2 kodlu takım daha iyi performans göstermiştir.

- En düşük ortalama yüzey pürüzlülüğü değerleri T1 kodlu takımda $450 \mathrm{~m} /$ dak kesme hızında meydana gelmiştir.

- Regresyon analizi sonucunda elde edilen modelin de başarı oranın yüksek olduğu görülmektedir.

\section{TEŞEKKÜR (ACKNOWLEDGMENTS)}

Yazarlar bu çalışmayı 0109.STZ.2013-1 kodlu proje ile destekleyen T.C. Bilim, Sanayi ve Teknoloji Bakanlığı'na teşekkür eder.

\section{KAYNAKLAR (REFERENCES)}

[1] Eren, Y. 2007 "Kompozit Yapıların Darbe Etkilerinin İncelenmesi”, Yüksek Lisans Tezi, Dumlupınar Üniversitesi Fen Bilimleri Enstitüsü, Kütahya

[2] Ersoy, M.S. 2005 "Lif Takviyeli Polimerik Kompozit Malzeme Tasarımı”, Yüksek Lisans Tezi, Kahramanmaraş Sütçü İmam Üniversitesi Fen Bilimleri Enstitüsü, Kahramanmaraş. 
[3] Rusinek, R. 2010 "Cutting process of composite materials:An experimental study", International Journal of Non-Linear Mechanics 45, 458-462.

[4] Kalla, D., Sheikh-Ahmad, J., Twomey, J. 2010 "Prediction of cutting forces in helical end milling fiber reinforced polymers", International Journal of Machine Tools and Manufacture, 50(10), 882-891

[5] Davim, J.P., Reis, P. 2005 "Damage and dimensional precision on milling carbon fiber-reinforced plastics using design experiments", Journal of Materials Processing Technology, 160:160-167.

[6] Akira, H., Naoya, H., Takashi, U., Tatsuaki, F. 2014 "High-quality machining of CFRP with high helix endmill”, Manufacturing Technology, 89-92

[7] Gaitonde, V. N., Karnik, S. R., Rubio, J. C., Correia, A. E., Abrao, A. M., Davim, J. P. 2008 “Analysis of parametric influence on delamination in high-speed drilling of carbon fiber reinforced plastic composites", Journal of materials processing technology, 203(1), 431-438.

[8] Shyha, I.S., Aspinwall, D.K., Soo, S.L., Bradley, S. 2009 "Drill geometry and operating effects when cutting small diameter holes", C. International Journal of Machine Tools\&Manufacture, 1008-1014.

[9] Davim, J.P., Rubio, J.C., Abrao, A.M. 2007 "A novel approach based on digital image analysis to evaluate the delamination factor after drilling composite laminates", Composite Science and Technology, 1939-1945.

[10] Davim, J.P., Reis, P. 2004 "Drilling carbon fiber reinforced plastics manufactured by autoclaveexperimental and statistical study", Materials and Design, 315-324

[11] Davim, J.P., Reis, P. 2003 "Study of delamination in drilling carbon fiber reinforced plastics (KFTK) using experiments", Composite Structures, 481-487

[12] Chen, W. C. 1997 "Some experimental investigations in the drilling of carbon fiber reinforced plastic (CFRP) composite laminates", International Journal of Machine Tools\&Manufacture, 1097-1108.

[13] Urban, N. A. 2005 "Analysis of machining quality in edge trimming of carbon fiber reinforced composite", Doctoral dissertation, Wichita State University, 21-36.

[14] Karpat, Y., Polat, N. 2013 "Mechanistic force modeling for milling of carbon fiber reinforced polymers with double helix tools", CIRP Annals - Manufacturing Technology 62, 95-98.

[15] Kurt, A. 2006 "Talaş kaldırma sırasında oluşan kesme kuvvetleri ve mekanik gerilmelerin deneysel olarak incelenmesi ve matematiksel modellerinin oluşturulması”, Doktora Tezi, Gazi Üniversitesi Fen Bilimleri Enstitüsü, Ankara.

[16] Sorrentino, L., Turchetta, S. 2011 "Milling of Carbon Fiber-Reinforced Plastics: Analysis of Cutting Forces and Surface Roughness" 18th International Conference On Composite Materials, Korea. [4] W. Hundsdorfer, J. G. Verwer, Numerical Solution of Time-Dependent Advection-Diffusion- Reactio

[17] Hill, T., Lewicki, P., Lewicki, P. 2006 "Statistics: methods and applications: a comprehensive reference for science, industry, and data mining", StatSoft, 21-35. [4] W. Hundsdorfer, J. G. Verwer, Numerical Solution of Time-Dependent Advection-Diffusion- Reactio

[18] Feito, N., Díaz-Álvarez, J., Díaz-Álvarez, A., Cantero, J. L., López-Puente, J., \& Miguelez, H. 2014 "Influence of Tool Geometry in Drilling", CFRP. ECCM16 - 16th European Conference On Composite Materials, Seville, Spain [4] W. Hundsdorfer, J. G. Verwer, Numerical Solution of Time-Dependent Advection-Diffusion- Reactio

[19] Çakıroğlu, R. 2011 "Delik Delme İşlemlerinde Kesme Parametrelerine Bağlı Olarak Oluşan Sicaklığın Modellenmesi”, Yüksek Lisans Tezi, Gazi Üniversitesi Fen Bilimleri Enstitüsü, Ankara. 